\title{
Finite Element Simulation on the Roller Pressure during the Rolling of Glass
}

\author{
Geng Tie, Hujin Zhong* \\ School of Mechanic \& Electrical Engineering, Henan University of Technology, Zhengzhou, China \\ Email: tiegeng2000@136.com, *15003882735@163.com
}

How to cite this paper: Tie, G. and Zhong, H.J. (2017) Finite Element Simulation on the Roller Pressure during the Rolling of Glass. Journal of Materials Science and Chemical Engineering, 5, 168-174. http://dx.doi.org/10.4236/msce.2017.51020

Received: March 17, 2017

Accepted: January 21, 2017

Published: January 24, 2017

\begin{abstract}
This article mainly carries on the finite element value simulation using the DEFORM-3D software to the glass rolling distortion process and mainly studies the relationship between the roller pressure and the forming roll diameter, the rotational speed as well as the under press rate. The result indicated that, its analogue result states the result basically with the traditional theory consistent.
\end{abstract}

\section{Keywords}

Glass, Rolling, Numerical Simulation

\section{Foreword}

Solar glass is a kind of patterned glass which is rolled special pattern on the glass surface, in order to maximize the photoelectric conversion efficiency of solar cells. The main method of solar glass production is the roll calender method. During the production of glass, raw materials dissolve in the melting pool which is in high temperature and introduce calender formation through flow channel [1]. One of calender rolls is smooth, the other is empaistic. There are some cooling water channels inside the calender rolls and patterns which are embossed on rolls are engraved on the surface of soft glass. Glass requires becoming solid quickly after rolling and pattern remains clear and sharp, there is no deformation and glass shows greatly crystal and blackout. On the one hand the calender roll causes the glass rolling formation; on the other hand it is mobile through the rotation hauling vitreous humor. In the process of rolling, the roller press is one of the most important technical parameters, equipment verification, stiffness, or production processes are inseparable from it. Roll pressure which affects the rolling, the life of the roller and the quality of the glass pieces etc, is the important parameters that adjust pressure, improve product quality and 
mine potentiality of the equipments. It is also the core setting model of glass rolling unit of the computer, and its setting accuracy can directly affect the roll gap setting, thereby affecting the stability of rolling parts, precision rolling and final rolling quality and so on. The roller pressure alters with the change of under press rate, roller diameter and rotational speed, it is difficult to control the precision of plate thickness and maintain the stability of production. Users put forward higher requirements to the thickness precision and flatness quality of photovoltaic glass, so the research of roller pressure has very importantly theoretical significance and practical value.

The glass rolling formation belongs to heat transfer problems which have something to do with freely moving boundary, non-Newtonian and non-isothermal melt flow. The traditional glass rolling formation craft and the mold design mainly depends upon designer's intuition, the experience and the experimental mold engineer's technique level [2]. In this kind of production process the method of trial-and-error which is based on experience causes the fact that the product development cycle is long, the cost is high and it is difficult to guarantee the quality of the products. With the increasingly high demand for glass, glass shapes and sizes update on faster and faster and increasingly high product quality requirements, so shortening product development cycles, improving product quality and reducing production costs are becoming urgent to enhance international competitiveness. But with the development of computer software and hardware technology, the finite element analysis software also obtains rapid improvement. It has become the new technical means by using finite element analysis software to solve the shortcomings of traditional glass production process. This paper simulates the facts which affect the roller pressure during the process of PV glass rolling by using DEFORM-3D software and obtains a reliable production process parameters which are used to guide the practical production with the help of image-text such as nephogram and isopleths to display simulation results.

\section{This Basic Hypothesis in the Process of Simulation}

\subsection{Viscoplastic Basic Assumptions}

When some complex technological process is simulated, it is appropriate to simplify the simulation process according to actual needs if the simulation calculation amount is so big. When we use the viscoplasticity finite element method analysis glass rolling formation question, the following basic assumptions for the necessary simplification are given.

1) Elastic strain is much smaller than the plastic strain, so it is necessary to ignore the elastic deformation of the material.

2) The material volume is incompressible.

3) Material has the isotropic characteristic.

4) Regardless of the body force (gravity and inertia force, etc.).

5) The pair of rolls is smooth.

6) In the forming process of the initial temperature distribution of roller, it 
often takes the average of the cooling water temperature.

\subsection{Model Establishments}

DEFORM-3D software supports a variety of CAD systems. This article establishes three-dimensional model of glass melt-water which is saved as STL and imported DEFORM-3d software through the Pro/E software. The size of calender roll is $\varnothing 300 \mathrm{~mm}$, glass melting body dimensions are $400 \mathrm{~mm} \times 200 \mathrm{~mm} \times 10$ $\mathrm{mm}$. Model grid is 30,000 which shows as Chart 1 , the simulation automatically repaints the mesh grid feature, designed to ensure correct simulations. In this simulation process the material of forming rolls is AISI-H-13 and the material of rolling is GLASS.

\subsection{Definition of Boundary}

Boundary conditions of the simulation include velocity boundary condition and friction boundary condition and thermal boundary condition. Velocity boundary conditions are used to solve the symmetrical problems by which speed of all nodes on symmetry plane are set as zero. In the contact face friction uses the cutting friction and the friction coefficient is 0.7 . For thermal boundary conditions, the ambient temperature is $20^{\circ} \mathrm{C}$. The heat flux is $54 \mathrm{w} / \mathrm{m}^{2}$.

\section{The Results of Numerical Simulation and Analysis}

\subsection{The Variation of the Roller Pressure during Glass Rolling}

The process of forming is very complicated, plastic deformation of glass melt only occurs near the local area of the calender roll. The whole process is divided into three stages when the glass melt contacts with the calender roll from the beginning to the end of the rolling. The roller pressure is different in the different stages of recycle flattening.

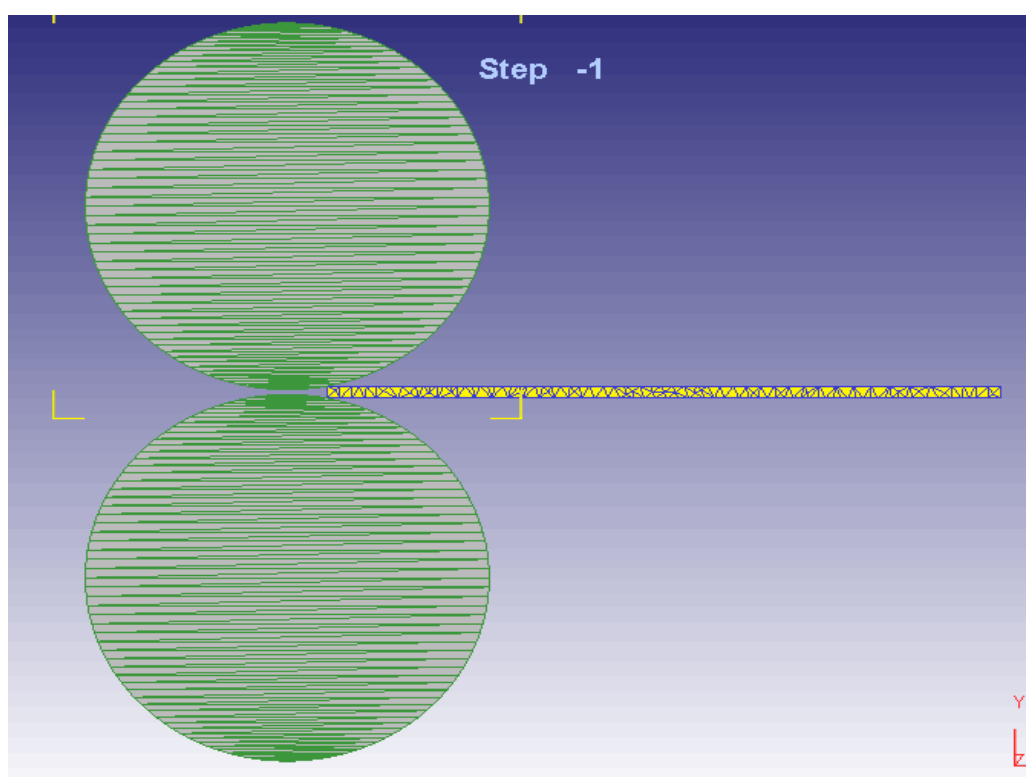

Chart 1. Model establishments. 
Seen from the simulation results on the Chart 2, in the process of rolling, the roller pressure rises rapidly at the beginning and this process description extends the stage for the unstable constant pressure, after the rolling enters the roller seam, the roller pressure undulates in a scope, this process description for stable rolling stage, after the rolling board leaves the roller seam, the roll pressure rapidly reduces to zero from some value. The reason why there is a undulation during the simulation of the roll pressure is that in the simulation of rolling process, rolling roller with regular polygon approximation round to establish numerical simulation [3], in the course of rotary rolling will inevitably result in small range calender roll eccentricity and reduction of small fluctuations, causing that force appears this kind of variation of volatility. The simulation results tally with the actual rolling, because in the actual process of rolling, rolling roll will have a few millimeters. Calender rollers beating itself is the cause of the error and different kind of roll diameters of ovality, therefore, in the actual process of glass the roller pressure will be volatile.

\subsection{Influence of the under Press Rate on the Roller Pressure}

The under press rate is an important factor affecting the roller pressure during the process of glass rolling, the roller pressure not only affects the stability of draw piece, rolling precision and rolling quality of the final effect, therefore it has some important significance to research the relationship between the under press rate and the roller pressure during the process of rolling.

As other conditions are in the same situation, the Chart 3 shows the result on the influence of the roller pressure when the under press rate is $20 \%, 40 \%$ and $60 \%$. Above three numbers are the simulation of roller pressure when they respectively are under the condition of $20 \%, 40 \%$ and $60 \%$ of the under press rate. Simulation results can be concluded from the figure that when the speed and diameter of rolling roller are same, the roller pressure increases with the rise of the under press rate. Because the under press rate increases will lead to the rise

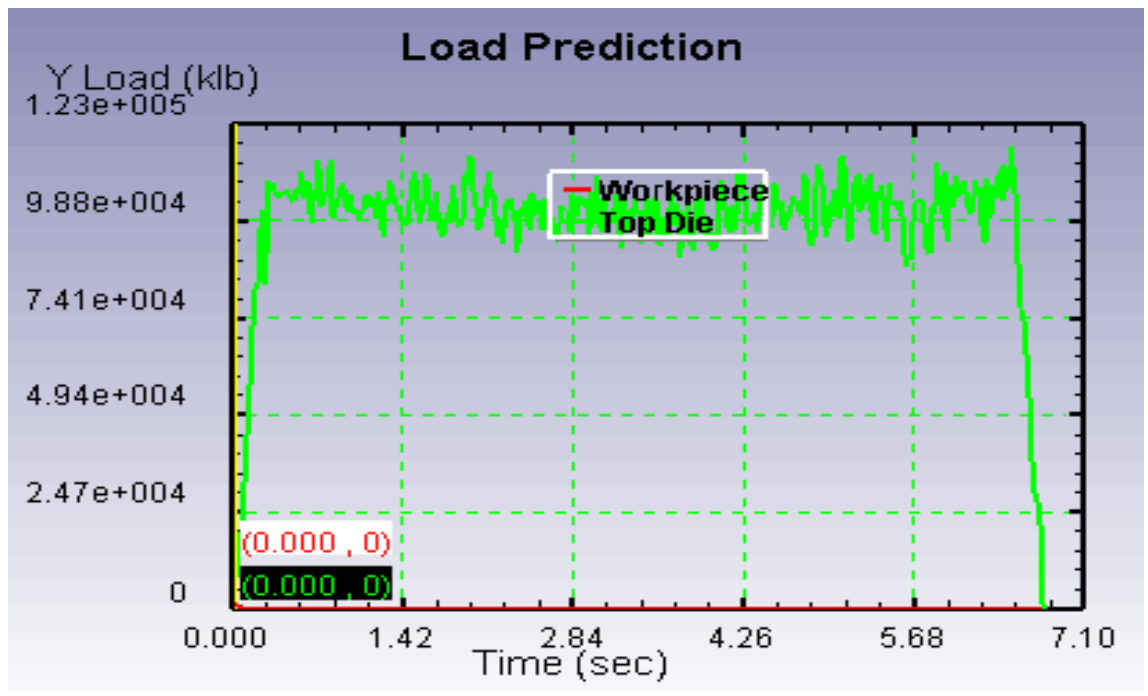

Chart 2. The results of numerical simulation and analysis. 


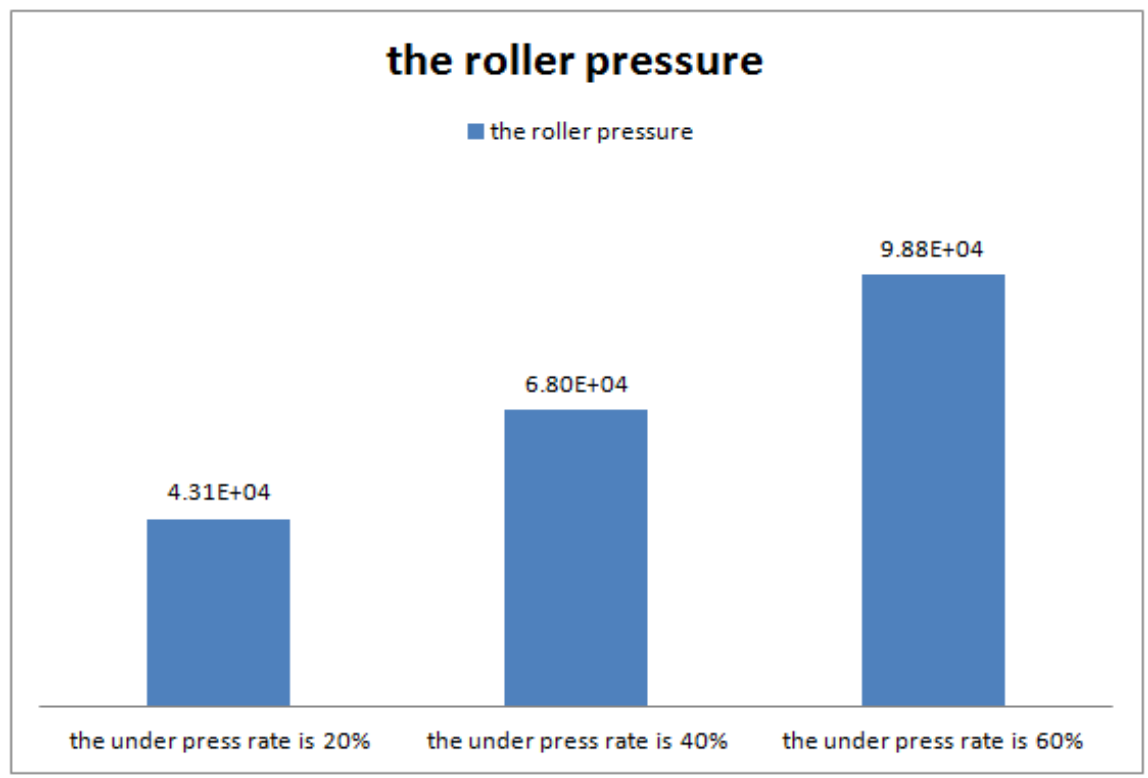

Chart 3. Influence of the under press rate on the roller pressure.

of the contact area between rolling and rolling rollers, the contact arc length enlarge, the influence of outside rubs and the average unit pressure; at the same time, by the increase of under press rate will lead to the increase of deformation resistance and will also make the roller pressure increase [4].

\subsection{Influence of the Diameter of Rolling Roll on the Roller Pressure}

In the forming process, selection of calender roll diameter is very important. Roller diameter is an important technical parameter of rolling photovoltaic glass, if the roller diameter is too large, then the mold cost increases and the manufacturing cost is high; if the roller diameter is too small, it has a certain effect on the forming quality. Therefore choosing a suitable diameter is very important to the rolling process of glass and analyzing the influence law of roller diameter on the roller pressure by the finite element software to provide a theoretical basis for forming economic production.

As other conditions are in the same situation, the Chart 4 shows the result on the influence of the roller pressure when the diameter of rolling roll is $300 \mathrm{~mm}$ and $500 \mathrm{~mm}$. Above numbers are the simulation of the roller pressure when the diameter of rolls is respectively $300 \mathrm{~mm}, 400 \mathrm{~mm}$ and $500 \mathrm{~mm}$. We can see from the analogue result that when the under press rate and speed of rolling roller are same, the roll pressure rises along with the increase of the rolling roller diameter. It is because that when the diameter of roller increases, the velocity of roller surface rises, so as to make rolling surface flow speed increase, which increases the roller pressure.

\subsection{Influence of the Speed of Rolling Roll on the Roller Pressure}

In the forming process, the speed of rolling rolls plays an important role in the 
glass forming quality. Changing the speed of rolling rolls, will make the deformation and the roller pressure to be changed, thus changing the shape and size of the deformation zone, which has an important influence on the forming process of quality and mechanical properties.

As other conditions are in the same situation, the Chart 5 shows the result on the influence of the roller pressure when the speed of rolling roll is $60 \mathrm{r} / \mathrm{min}$ and $120 \mathrm{r} / \mathrm{min}$. Above are the simulation of the roll pressure when the speed of rolls is respectively $60 \mathrm{r} / \mathrm{min}, 90 \mathrm{r} / \mathrm{min}$ and $120 \mathrm{r} / \mathrm{min}$. we can see from the chart that the roll pressure rises along with the increase of the forming rolls speed. Because the increase of drawing roller speed will cause the increase of strain rate which results in the rise of force. Due to the glass melt through the rollers, the vitreous humor can have the downward action to its contact lower roll, the vitreous humor also can have the upward action to the contact upper roll, when the strength is big enough, roller bending deformation caused by rolling out will appear and

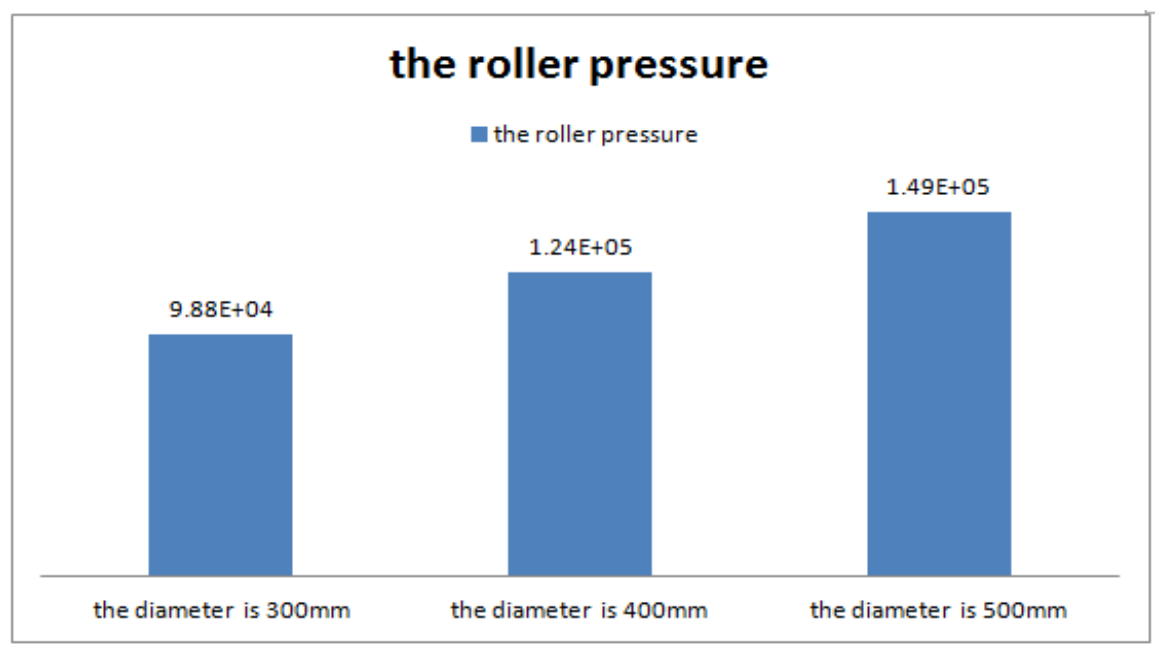

Chart 4. Influence of the diameter of rolling roll on the roller pressure.

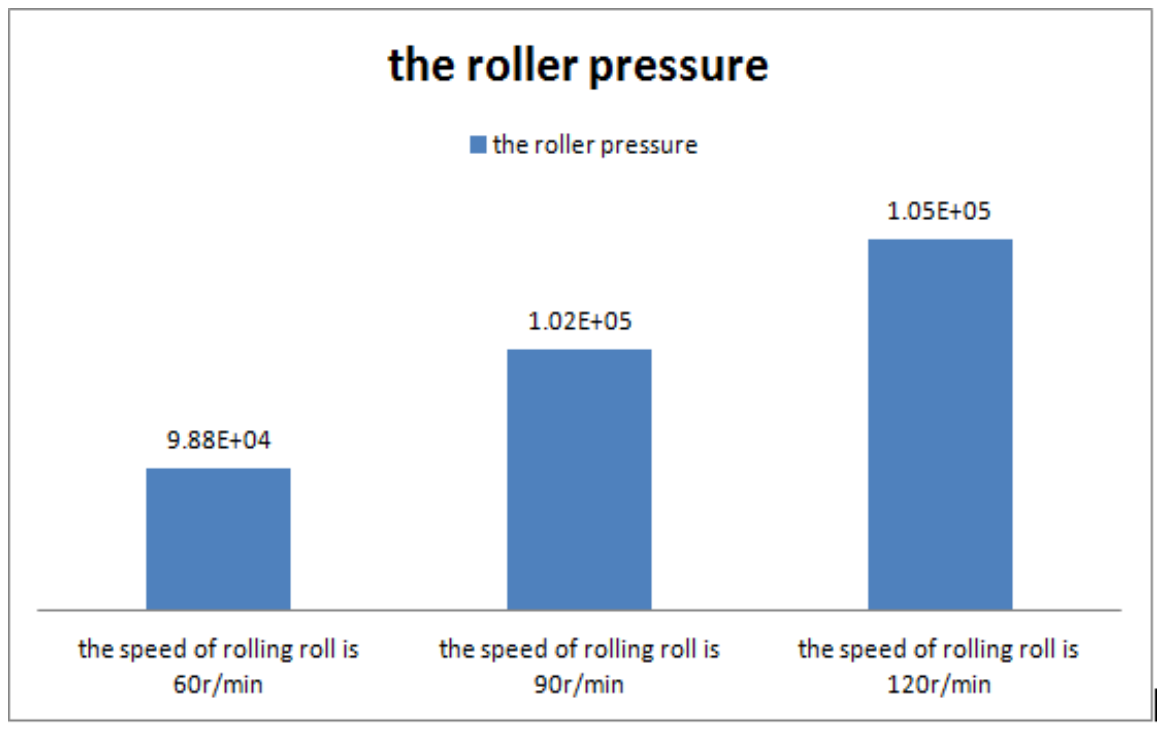

Chart 5. Influence of the speed of rolling roll on the roller pressure. 
photovoltaic glass show the middle thick, thin features on both sides [5]. So the simulation has a certain theoretical guiding significance and practical economic value to the actual production of glass factories.

\section{Summary}

The simulation results of finite element software DEFORM-3d show that under the condition that the speed and the diameter of rolling roller are certain, the roller pressure rises along with the increase of the under press rate; under the condition that the speed and the under press rate of rolling roller are certain, the roller pressure extends the strength to increase along with the increase of forming rolls diameter; under the condition that the under press rate and the diameter of rolling roller are certain, the roller pressure extends the strength to increase along with the forming rolls speed promotion.

\section{Acknowledgements}

The authors would like to acknowledge financial support from the National Natural Science Foundation of China (Grant No. 51375143) and the Talents Project of Universities of Henan Province (2015RCJH12).

\section{References}

[1] Fei, M.Q. (2010) Analysis on the Production Process of Photovoltaic Glass. Solar Energy, 5. http://www.docin.com/p-92712652.html

[2] Zhou, H.M., Xi, G.D. and Li, D.Q. (2007) Mathematical Modeling and Simulation of Residual Stress in Bulb Compression Molding. Science in China (Series E).

[3] Zheng, B. and Zhang, H.H. (2009) Finite Element Simulation on the Rolling Force during Hot Rolling of Steel Plate. Wide and Heavy Plate, 15.

[4] Jiang, J.X., Zheng, H.W., Wu, H.B. and Yang, L. (2012) Study on Thermal Deformation Resistance of X120 Pipeline Steel. Heat Treatment Technology and Equipment, 33.

[5] Chen, X.-L. and Wang, Y.-X. (2015) Analysis of Photovoltaic Glass Rolling Thickness Range. Science and Technology, 31. 